\title{
Tenofovir in the Management of Chronic Hepatitis B Infection During Pregnancy
}

\author{
Ayhan Hilmi Çekin', Yeşim Çekin² \\ ${ }^{1}$ Clinic of Gastroenterology, Antalya Research and Training Hospital, Antalya, Turkey \\ ${ }^{2}$ Clinic of Microbiology, Antalya Research and Training Hospital, Antalya, Turkey
}

\begin{abstract}
Chronic hepatitis B infection has a worldwide distribution, with approximately 350 million infected persons. While become more of an issue during pregnancy concerning maternal and fetal well-being and the influence of pregnancy itself on the course of the disease; the natural history of chronic hepatitis B infection during pregnancy has not been clearly established. This paper reports the outcome of pregnancy in a patient with chronic hepatitis B infection who discontinued double antiviral treatment since she wanted to get pregnant but then was administered tenofovir disoproxil fumarate (TDF;
\end{abstract} $245 \mathrm{mg} /$ day) monotherapy at the $32^{\text {nd }}$ gestational week.

Key Words: Tenofovir, hepatitis B, pregnancy

Received: 14.06.2011 Accepted: 21.11.2011

\section{Introduction}

Affecting 350 to 400 million individuals worldwide, Hepatitis $B$ virus (HBV) remains a global health problem despite proper vaccination because acquirement of the infection resides either perinatally or in early childhood exposure in half of the infected population in countries with high rates of $\mathrm{HBeAg}$ positive infections in women of child-bearing age (1-3).

Pregnancy is known as an immunological counterbalance between maternal tolerance of paternal and fetal MHC antigens and that of maintaining immune-competence for defense against microbes and other antigens (4). Hepatitis B infection during pregnancy has been associated with special terms and conditions such as maternal and fetal effects of hepatitis $B$, effects of pregnancy itself on the course of hepatitis B infection, treatment of hepatitis B during pregnancy and prevention of perinatal infection (5). Therefore, the question arises about what to do if a young woman on therapy becomes pregnant or plans to become pregnant (6).

To be familiar with the natural history of chronic HBV infection in the peri-partum period has been considered essential, as the detection and management of abnormal liver function in the pregnant female is an uphill struggle (4). Nevertheless, much has been documented about peri-natal mother to newborn transmission of HBV and the possible modes of prevention, but data concerning the effect of chronic maternal infection on pregnancy outcome as well as the effect of pregnancy on maternal HBV disease in the chronically infected mothers are limited and controversial $(3,4,7)$. From this point of view, this paper presents the outcome of pregnancy in a patient with chronic hepatitis $B$ infection who was administered te- nofovir disoproxil fumarate (TDF; $245 \mathrm{mg} /$ day) monotherapy at the $32^{\text {nd }}$ gestational week due to risks related to high viral load.

\section{Case Report}

A 28-year-old woman was identified with $\mathrm{HBsAg}$ positivity, HBeAg positivity, HBV DNA level of $>640,000,000$ copies/ $\mathrm{mL}$ (Roche-Combas-Taqman), minimally high levels of ALT 51 IU/L (5-45 IU/L) and Delta Ab negativity at her initial diagnosis of hepatitis during family screening for the disease, which was primarily detected in his father. She had been on follow up in our clinic since July 2005. Pre-treatment liver biopsy revealed Hepatic Activity Index (HAl) of 12 and the diagnosis of fibrosis 3 (Ishiac score) chronic hepatitis B with $\mathrm{HBeAg}$ positivity and HBV DNA $>640,000,000$. Pegylated interpheron 2a $(180 \mu \mathrm{g} /$ week; s.c.) was initiated on July 11 2006. There was no decline in HBV DNA titers despite normalization of ALT- AST levels after 2 months. Treatment was discontinued after 20 weeks due to determination of HBV DNA $640,000,000$ copies/mL and $\mathrm{HBeAg}(+)$ as well as significant side effects of interferon, including depression, severe headache, weight loss, hair loss and skin lesions at the injection site. Lamivudin $(100 \mathrm{mg} /$ day; oral) treatment was initiated. Later on, adefovir $(10 \mathrm{mg} /$ day; oral) was added to the treatment due to failure in expected decrease in the viral load with antiviral monotherapy. Normal ALT levels, HBV DNA titers of 10,000 copies $/ \mathrm{mL}$ and ongoing $\mathrm{HBeAg}$ positivity were evident on the last evaluation despite ongoing combined treatment with lamivudin and adefovir. The patient was admitted to our department at this stage as a married woman for 4 years planning for a pregnancy. 
The risk of rapid progression to cirrhosis during drug-free periods due to lack of complete suppression of the viral load and the high hepatic activity, together with fibrosis in the past course of the disease necessitated rigorous pregnancy planning in terms of well being of both baby and the mother. Pregnancy under ongoing antiviral treatment was not approved by the patient or the physician due to the high risk associated with adefovir therapy. Therefore, pregnancy was planned with deferral of antiviral drugs.

Antiviral drugs were discontinued. Patient became pregnant after four months, during which HBV DNA was measured to be $>640,000,000$ copies $/ \mathrm{mL}$. Increase in ALT during the drug-free period was gradual as recorded to be $63 \mathrm{IU} / \mathrm{L}$ (5-45 IU/L) in the first month and $126 \mathrm{IU} / \mathrm{L}$ (5-45 IU/L) in the last month of the pregnancy. Mutation analysis for drug resistance was performed due to an established increase in HBV DNA titers. After DNA isolation 80, 173, 180, 181, 204, 236 numbered codons of HBV polymerase gene were screened by the multiplex PCR method during mutation analysis. Additionally, mutation analysis was also performed for RT gene (amino acids from 131 to 210) and S gene (amino acids from 119 to 201). No mutation was observed, indicating absence of drug resistance. Tenofovir disoproxil fumarate (TDF; $245 \mathrm{mg} /$ day; oral) was initiated at the $32^{\text {nd }}$ week of pregnancy. Preterm delivery occurred at the $37^{\text {th }}$ gestational week due to a severe urinary infection related to kidney stone. Hepatitis B Immunoglobulin and vaccine were administered to the newborn baby, who is still healthy without any problems. ALT levels were normalized at the second month of TDF treatment after high levels which ranged between $100 \mathrm{IU} / \mathrm{L}$ and $130 \mathrm{IU} / \mathrm{L}$ (5-45 IU/L) for the initial months. HBV DNA titer measured to be $>640000000$ copies $/ \mathrm{mL}$ at the beginning of the tenofovir treatment was determined to regress to $<300$ copies $/ \mathrm{mL}$ at the $4^{\text {th }}$ month of the treatment. The patient is still on TDF $(245$ $\mathrm{mg} /$ day) monotherapy without any sign of decompensation of her liver disease with ALT levels of normal range. Immunization schedule was completed in the baby who had a high titer Anti-HbsAb positivity.

\section{Discussion}

Owing to several challenges of hepatitis B treatment in pregnancy, including contraindications related to interferon use and lack of detailed evaluations concerning use of nucleoside analogs with activity against HBV in pregnant women, patients on antiviral therapy for hepatitis $B$ are recommended to practice birth control (6). What is more, tenofovir and telbivudine are considered "Category $B$ ", indicating that they have been found to be safe in animal models and there is limited data in humans. In contrast, lamivudine, adefovir, and entecavir are considered "Category C", indicating that their safety has not been shown adequately either in animal models or humans (6).

In this regard, it is well-advised to defer therapy until after delivery in order to avoid fetal exposure to the therapeutic agents, unless maternal liver disease requires treatment, or a pregnancy occurs in a woman already receiving a medication for HBV (5). Thus, antiviral therapy during pregnancy was documented to be an option for women with high viral loads as long as a comprehensive discussion of risks and benefits has been considered, since limited data are evident, while use of lamivudine, tenofovir, or telbivudine starting early in the $3^{\text {rd }}$ trimester of pregnancy becomes the common strategy for therapy (8).

Based on safety data in pregnancy which are most robust, with lamivudine and tenofovir compared with other therapies (8), use of tenofovir in pregnancy was documented to be associated with a risk not higher than other antiretroviral drugs or the general population in the first trimester of pregnancy (9). As a matter of fact, selection of TDF (245 mg/day) for the management of high viremia which persisted to late pregnancy in our patient seems reasonable based on published reports signifying potent inhibitory activity of TDF against the wild-type and drug-resistant mutants in the treatment of hepatitis $(10,11)$, also, consideration of the drug in "Category B" indicating safety in animal models despite limited data in humans (6). In fact, among agents classified as FDA pregnancy risk category $B$, only tenofovir received this classification based on data collected in human exposure (8). The clinical trial with tenofovir in pregnant women consisting 879 women in their first trimester and 501 in the second and third trimester revealed the rate of birth defects associated with tenofovir to $2.2 \%$, which is similar to the background rate (9). Furthermore continuation of TDF treatment after delivery is also in line with the recommendations concerning use of antiviral therapy after delivery with respect to indications expressed in available HBV guidelines (5).

Accordingly, despite the gradual and slow rise in ALT levels observed in our patient during the course of pregnancy, persistently high levels of viral load necessitated the implementation of antiviral therapy at the $32^{\text {nd }}$ gestational week in correlation with the past history of the disease lacking complete suppression of the viral load as long as 4 year-follow up.

Several local and systemic non-specific suppressor mechanisms operating during pregnancy to down-regulate maternal immune responses for fetal protection were also documented to affect the evolution of chronic HBV infection $(12,13)$. Hence, it has been stated that a relatively immune-compromised state in the second and third trimesters of pregnancy associated with high levels of adrenal corticosteroids may facilitate viral replication leading to the increase in viral load (5). Therefore, while considered to do well during pregnancy in general, women with chronic hepatitis B infection may also suffer from high viremia, which was documented to reach a peak in the third trimester of pregnancy, reducing maternal immune-competence and thus disturbing the orchestration of an immune-clearance of $\operatorname{HBV}(4,13)$.

Since maternal HBeAg positivity, HBsAg titer and HBV DNA level are considered among the risk factors for transplacental transmission of HBV (14), our administration of HBIG and HBV vaccine which is a regimen considered to be effective in preventing transmission of hepatitis B in more than $95 \%$ of children, seems to be in line with current recommendations for prevention of maternal-infant transmission of hepatitis $B(6,15)$.

Albeit $80 \%$ of preterm births have been considered to be spontaneous resulting from maternal infection or inflammation, uteroplacental ischemia or hemorrhage, uterine over- 
distension, and immunologically mediated processes (16), the effects of chronic HBV infection on pregnancy outcomes have not been clearly defined and the data are controversial.

In this context, while lack of any significant differences was reported in terms of gestational age at delivery, birth weight, incidence of prematurity, neonatal jaundice, congenital anomalies and perinatal mortality in HBsAg-positive women when compared to controls (17), retrospective evaluation of chronic maternal HBV infection on pregnancy outcome revealed that a chronic HBV infection in the pregnant woman may contribute to premature birth because of low grade inflammation due to the release of pro-inflammatory cytokines $(7,17)$. Whilst still subject to further investigation, pregnancy outcome in our case supports the suggested association of pregnancy of a mother with chronic HBV infection with preterm delivery $(5,17)$.

Actually, a decreased possibility of materno-fetal transmission as well as low probability of birth defects were the key factors effective in convincing the mother to use TDF during pregnancy. Nevertheless she questioned the possible role of TDF treatment in the premature birth of her baby, which in fact occurred due to severe urinary infection related to kidney stone.

\section{Conclusion}

The findings of our case report suggest that deferral of antiviral therapy until delivery during pregnancy in chronic hepatitis B infection lacking complete suppression of viral load is likely to be associated with a gradual serum ALT elevation and an abrupt and persistent increase in viral load.This reaches a peak in the third trimester and necessitating implementation of antiviral treatment. Hence, TDF monotherapy $(245 \mathrm{mg} /$ day) seems to be safe and effective in achievement of a pronounced reduction in persistently high maternal viral load to $<300$ copies/mL which is much better than before the pregnancy and the normalization of hepatic enzymes even after a treatment-free period lasting almost for a year. When considered from the fetal aspect, the contribution to the prevention of materno-fetal transmission during pregnancy seems another success of TDF monotherapy. While large scale, prospective studies are necessary to clarify the interplay of pregnancy and chronic hepatitis $B$, the role of closer follow-up of chronic HBV-infected, pregnant females seems essential for the effective management of the disease to avoid potentially serious maternal morbidity and mortality.

\section{Conflict of Interest}

No conflict of interest was declared by the authors.

\section{References}

1. Dienstag JL, Hepatitis B. virus infection. $N$ Engl J Med 2008;359:1486-500. [CrossRef]

2. Reynaud L, Carleo MA, Talamo M, Borgia G. Tenofovir and its potential in the treatment of hepatitis B virus. Ther Clin Risk Manag 2009;5:177-85.

3. Alter MJ. Epidemiology of hepatitis B in Europe and worldwide. J Hepatol 2003;39:64-9. [CrossRef]

4. Tan HH, Lui HF, Chow WC. Chronic hepatitis B virus (HBV) infection in pregnancy. Hepatol Int 2008;2:370-5. [CrossRef]

5. Jonas MM. Hepatitis $B$ and pregnancy: an underestimated issue. Liver Int 2009;291:133-9. [CrossRef]

6. Peters MG. Special populations with hepatitis B virus infection. Hepatology 2009;49:S146-55. [CrossRef]

7. Elefsiniotis I, Tsoumakas K, Vezali E, Glynou I, Drakoulis N, Saroglou G. Spontaneous preterm birth in women with chronic hepatitis B virus infection. Int J Gynecol Obstet 2010.

8. Tran TT. Management of hepatitis B in pregnancy: weighing the options. Cleve Clin J Med 2009;76:S25-9. [CrossRef]

9. Antiretroviral Pregnancy Registry: Available at http://www.apregistry.com.Accessed August 2010.

10. van Bommel $F$, Wunsche $T$, Mauss $S$, Reinke $P$, Bergk $A$, Schürmann $D$, et al. Comparison of adefovir and tenofovir in the treatment of lamivudine-resistant hepatitis B virus infection. Hepatology 2004;40:1421-5. [CrossRef]

11. van Bommel F, Zollner B, Sarrazin C, Spengler U, Huppe D, Möller $B$, et al. Tenofovir for patients with lamivudine-resistant hepatitis $B$ virus (HBV) infection and high HBV DNA level during adefovir therapy. Hepatology 2006;44:318-25. [CrossRef]

12. Sargent IL. Maternal and fetal immune responses during pregnancy. Exp Clin Immunogenet 1993;10:85-102.

13. Gervais A, Bacq Y, Bernuau J, Martinot M, Auperin A, Boyer N, et al. Decrease in serum ALT and increase in serum HCV RNA during pregnancy in women with chronic hepatitis C. J Hepatol 2000;32:293-9. [CrossRef]

14. Xu DZ, Yan YP, Choi BC, Xu JQ, Men K, Zhang JX, et al. Risk factors and mechanism of transplacental transmission of hepatitis $B$ virus: a case- control study. J Med Virol 2002;67:20-6. [CrossRef]

15. Bzowej NH. Hepatitis $B$ therapy in pregnancy. Curr Hepatitis Rep 2010;9:197-204. [CrossRef]

16. Romero R, Espinoza J, Kusanovic JP, Gotsch F, Hassan S, Erez O, et al. The preterm parturition syndrome. BJOG 2006;113:17-42. [CrossRef]

17. Wong $S$, Chan LY, Yu V, Ho L. Hepatitis B carrier and perinatal outcome in singleton pregnancy. Am J Perinatol 1999;16:485-8. [CrossRef] 